\title{
Preparation and use of a Grafted Silica with Imidazole Groups for Cadmium Sorption and Subsequent Voltammetric Detection of Ascorbic Acid
}

\author{
Tayla Fernanda Serantoni da Silveira ${ }^{1}$. Daniela Silvestrini Fernandes ${ }^{1}$. \\ Priscila Fernanda P. Barbosa ${ }^{1}$. Devaney Ribeiro do Carmo ${ }^{1}$
}

Received: 6 March 2016 / Accepted: 5 October 2016 / Published online: 24 May 2017

(c) Springer Science+Business Media Dordrecht 2017

\begin{abstract}
Inorganic-organic hybrid materials, such as silica gel functionalized with an organic group, offer many applications in several areas of interest. The adsorptive properties provided by these materials due to the presence of active donor atoms such as $\mathrm{O}, \mathrm{N}$ and $\mathrm{S}$ of grafted organic groups, suggests their application in metal ions adsorption as well as in the preparation of electrochemical sensors for substances of interest. In this work a hybrid material formed by interaction of a 3-chloropropyl silica gel modified with imidazole was characterized by techniques such as infrared spectroscopy, ${ }^{29} \mathrm{Si}$ and ${ }^{13} \mathrm{C}$ nuclear magnetic resonance and analysis of surface area and porosity. Adsorption studies were carried out for cadmium (II) in different media, and the quantity of adsorbed metal increased according the following order of solvents: water $<$ ethanol $42 \%$ $<$ ethanol 99\%. After cadmium ions adsorption, the material was reacted with potassium hexacyanoferrate forming the material CdHSGI that was incorporated into a graphite paste electrode. Electrochemical studies were conducted with cyclic voltammetry. The cyclic voltammogram showed one redox couple with average potential $\mathrm{E}^{\theta^{\prime}}=0.25 \mathrm{~V}$ ( vs $\mathrm{Ag} / \mathrm{AgCl}, \mathrm{NaNO}_{3} 1.0 \mathrm{~mol} \mathrm{~L}^{-1} ; v=20 \mathrm{mVs}^{-1}$ ), attributed to the $\mathrm{Fe}^{2+}(\mathrm{CN})_{6} / \mathrm{Fe}^{3+}(\mathrm{CN})_{6}$ process. The modified electrode allowed the electrocatalytic ascorbic acid determination. Through voltammograms it was possible to observe a linear range from $1.0 \times 10^{-4} \mathrm{~mol} \mathrm{~L}^{-1}$ to $9.0 \times 10^{-4} \mathrm{~mol}$ $\mathrm{L}^{-1}(R=0.996)$ for the ascorbic acid determination with a
\end{abstract}

Devaney Ribeiro do Carmo docarmo@dfq.feis.unesp.br

1 Departamento de Física e Química, Faculdade de Engenharia de Ilha Solteira, UNESP - Universidade Estadual Paulista, Av. Brasil Centro, 56 CEP 15385-000, Ilha Solteira, SP, Brazil detection limit of $7.9 \times 10^{-5} \mathrm{~mol} \mathrm{~L}^{-1}$ with a relative standard deviation of $3 \%(n=3)$ and amperometric sensitivity of $11.1 \mathrm{~mA} / \mathrm{mol} \mathrm{L}^{-1}$.

Keywords Silica gel · Imidazole · Adsorption ·

Voltammetry · Graphite paste electrode $\cdot$ Ascorbic acid

\section{Introduction}

Silica gel is among the most widely used material as a matrix for making adsorbents. This inorganic polymer has a structure consisting of tetrahedral units of $\mathrm{SiO}_{4}$ linked by siloxane bridges $\mathrm{Si}-\mathrm{O}-\mathrm{Si}$ with a large number of silanol groups (Si-OH) distributed on its surface [1, 2]. Silica gel use as supports is associated with properties such as excellent thermal and mechanical stability, unique large surface area and well-modified surface properties [2-4]. The hybrid inorganic-organic materials such as silica gel functionalized with an organic group, offer many current potential applications of interest and can have outstanding properties in areas such as adsorbents, since studies suggest that the behavior of these materials used as adsorbents is mainly dependent on active donor atoms presence such as $\mathrm{O}, \mathrm{N}$ and $\mathrm{S}$ of grafted organic groups [2,5]. The most common method of modifying the silica gel surface involves the reaction of the surface hydroxyl groups with a silylating agent which acts as a precursor for the immobilization of additional organic groups $[1,2,6]$.

Imidazole, also known as 1,3-diaza-2,4-cyclopentadiene and officially designated as 1,3-diazole, is an organic compound of molecular formula $\mathrm{C}_{3} \mathrm{H}_{4} \mathrm{~N}_{2}$ [7] and part of the structure of important biological molecules [7, 8]. Imidazole has the ability to coordinate with a variety of transition metal ions due to the nitrogen donor atoms presence $[9,10]$. 
However, for metal ions adsorption from aqueous solutions use, the imidazole group needs to undergo a type of chemical modification by grafting onto a solid matrix, such as silica gel, to help overcome deficiencies such as toxicity and solubility in water [10].

In this work, 3-chloropropyl silica gel (SG) was organofunctionalized with imidazole groups in order to evaluate the adsorption capacity of metal ions in different media and test it as a new material to prepare electrochemical sensors for biological substances of interest, for example, ascorbic acid (AA). The development of a selective, simple and accurate method for the AA determination is of fundamental importance, due to the increased interest in the oxidative changes in food and recent advances in the pharmaceutical industries. Many methods for the AA determination are available [11], for example, enzymatic methods [14], titration [15], high performance liquid chromatography (HPLC) [16] and UV-vis detection [17]. However, most of these methods have disadvantages such as lack of reproducibility, sensitivity and selectivity [11]. Among the methods studied is the electrochemical method, which owing to its selectivity and sensitivity has received considerable attention, however, it is known that the accurate AA determination using conventional electrodes is very difficult due to their high overpotential. Therefore chemically modified electrodes with silica or silsesquioxane organically functionalized have been used for this purpose associated with techniques such as cyclic voltammetry; but the silica is the cheaper and easier material handle $[18,19]$.

\section{Experimental}

\subsection{Reagents and Solutions}

All reagents and solvents were of analytical grade and were used as purchased. All solutions and supporting electrolytes were prepared using Milli-Q water. Ascorbic acid was used without further purification and ascorbic acid solutions were prepared immediately before use.

\subsection{Synthesis of 3-chloropropyl Silica Gel (SG)}

The silica gel used in the present work was previously dried at $150{ }^{\circ} \mathrm{C}$ under vacuum for 4 hours. Then, $160 \mathrm{~g}$ of activated silica gel and $55 \mathrm{~mL}$ of 3chloropropyltrimethoxysilane were added to $350 \mathrm{~mL}$ of dry toluene. The mixture was maintained under reflux and stirring at $150{ }^{\circ} \mathrm{C}$ for 40 hours, under nitrogen atmosphere.

The 3-chloropropyl silica gel resulting was filtered and then washed with dry toluene using a Soxhlet system to extract the 3-chloropropyltrimethoxysilane unreacted with the silica matrix, and subsequently with ethanol. The final product obtained was denoted by SG. Figure 1a shows a representative scheme of this synthesis.

\subsection{Organofunctionalization of 3-chloropropyl Silica Gel with Imidazole}

3-chloropropyl silica gel (SG) organofunctionalization with imidazole was conducted according to a procedure described in the literature [20] with some modifications.

In a 3-neck flask were added $10 \mathrm{~g}$ of 3-chloropropyl silica gel (SG), $5.9 \mathrm{~g}\left(8.7 \times 10^{-2} \mathrm{~mol}\right)$ of imidazole and approximately $200 \mathrm{~mL}$ of xylene. The mixture was refluxed at $150{ }^{\circ} \mathrm{C}$ with constant stirring for 96 hours. The organofunctionalized material was separated in a sintered funnel and washed with methanol in a Soxhlet extractor for 48 hours. The product was dried at $100{ }^{\circ} \mathrm{C}$ for 4 hours and designated as SGI. The functionalization of SG is schematized in Fig. $1 b$.

\subsection{Isotherms of Adsorption}

The batch technique was employed for studies of the adsorptive capacity of organofunctionalized material (SGI) for $\mathrm{Cd}^{2+}$ ions from different media (aqueous, ethanol $42 \%$ and ethanol 99\%). For each adsorption isotherm, samples containing $0.050 \mathrm{~g}$ of SGI in $50 \mathrm{~mL}$ solvent with variable concentrations of cadmium chloride $\left(0.25 \times 10^{-3}\right.$ to $3.0 \times 10^{-3} \mathrm{~mol} \mathrm{~L}^{-1}$ ) were mechanically stirred for about 60 minutes, at a constant temperature of $25 \pm 1{ }^{\circ} \mathrm{C}$. The metal
Fig. 1 Representative scheme of the a preparation of 3-chloropropyl silica gel and $\mathbf{b}$ organofunctionalization of

3-chloropropyl silica gel (SG)

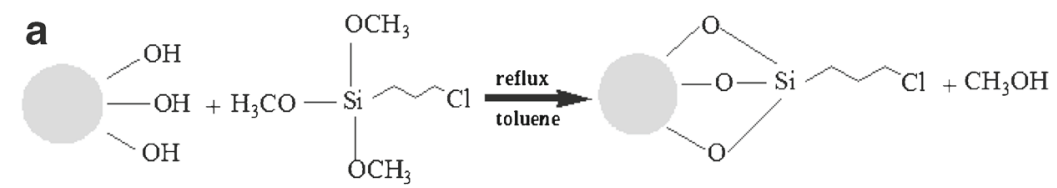

b

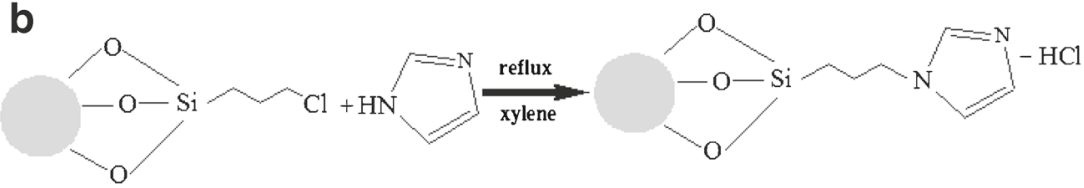


ion concentration in solution, in equilibrium with the solid phase, was determined by separating the solid phase and titrating with different aliquots of solution containing the metallic ion $\left(\mathrm{Cd}^{2+}\right)$ using the facile Rao and Shetty method with some modifications [21]. The quantity of adsorbed metal, $N_{f}$, in each flask was determined by the following equation:

$N_{f}=\frac{N_{a}-N_{s}}{m}$

where $m$ is the mass (g) of adsorbent and $N_{a}$ and $N_{s}$ are the initial and the equilibrium amount of the number of moles of the metal in the solution phase, respectively.

\subsection{Formation of Complex CdHSGI}

The CdHSGI complex was prepared as follows: $1.0 \mathrm{~g}$ of SGI was added to $25 \mathrm{~mL}$ of cadmium chloride aqueous solution $1.0 \times 10^{-3} \mathrm{~mol} \mathrm{~L}^{-1}$. The mixture was stirred for $1 \mathrm{~h}$ at room temperature. The solid phase was then filtered and washed thoroughly with deionized water. The material resulting from this first phase was dried at $70{ }^{\circ} \mathrm{C}$ and designated as CdSGI. In the second stage, the CdSGI was added to 1.0 $\times 10^{-3} \mathrm{~mol} \mathrm{~L}^{-1}$ potassium hexacyanoferrate (III) solution and the mixture was stirred for $1 \mathrm{~h}$ at room temperature and then the solid was thoroughly filtered, washed with deionized water and dried at $70{ }^{\circ} \mathrm{C}$. The material resulting from this stage was designated as CdHSGI.

\subsection{Preparation of the Graphite Paste Electrode Modified with CdHSGI}

Cyclic voltammograms were performed using the AUTOLAB PGSTAT potentiostat. The three electrode systems used in this study consisted of a modified working electrode (graphite paste electrode - GPE - CdHSGI), an $\mathrm{Ag} / \mathrm{AgCl}$ (sat.) reference electrode, and a platinum wire as the auxiliary electrode. The measurements were carried out at $25^{\circ} \mathrm{C}$. The graphite paste electrode modified with CdHSGI was prepared by mixing $40 \mathrm{mg}$ of CdHSGI with $60 \mathrm{mg}$ of graphite (Aldrich) and $50 \mu \mathrm{L}$ of mineral oil. The electrode body was produced from a glass tube of $3 \mathrm{~mm}$ i.d. and $14 \mathrm{~cm}$ height, containing graphite paste. A copper wire was inserted through the opposite end of the glass tube to establish electrical contact. The modified paste, after homogenization, was positioned on the tube tip to avoid possible air gaps, which often enhance electrode resistance [22].

\subsection{Procedure}

For the CdHSGI voltammetric behavior study a system was used of three electrodes: a modified working electrode (graphite paste electrode), an $\mathrm{Ag} / \mathrm{AgCl}\left(\mathrm{KCl} 3.0\right.$ mol. $\mathrm{L}^{-1}$ ) reference electrode, and a platinum wire as the auxiliary electrode. The solutions were prepared immediately before use and were deaerated with nitrogen. In most of the experiments, $1.0 \mathrm{~mol} \mathrm{~L}^{-1} \mathrm{NaNO}_{3}(\mathrm{pH} \sim 6.6)$ was used as the supporting electrolyte. In the determination study of ascorbic acid sensibility by graphite paste electrode modified with CdHSGI, the current intensity was estimated by the difference between the electrode current in the presence of analyte compounds and that which was established in the blank solution.

\subsection{Techniques}

\subsubsection{Fourier Transform Infrared Spectra}

The FTIR spectra were recorded on a Nicolet 5DXB FTIR spectrometer. About $150 \mathrm{mg}$ of $\mathrm{KBr}$ were ground in a mortar and a sufficient quantity of the solid sample was ground with $\mathrm{KBr}$ to produce a $1 \mathrm{wt} . \%$ mixture resulting in pellets. For the data collection a minimum of 64 scans was collected for each sample at a resolution of $\pm 4 \mathrm{~cm}^{-1}$ in the range 4000 to $400 \mathrm{~cm}^{-1}$.

\subsubsection{NMR Solid State Analysis}

All ${ }^{29}$ Si NMR (59.5 MHz) and ${ }^{13} \mathrm{C}$ NMR (75.4 MHz) solid state analyses were recorded on a Varian INOVA 300 spectrometer. The samples were packed in zirconia rotors and spun at the magic angle at $4500 \mathrm{~Hz}$, after relaxation delay

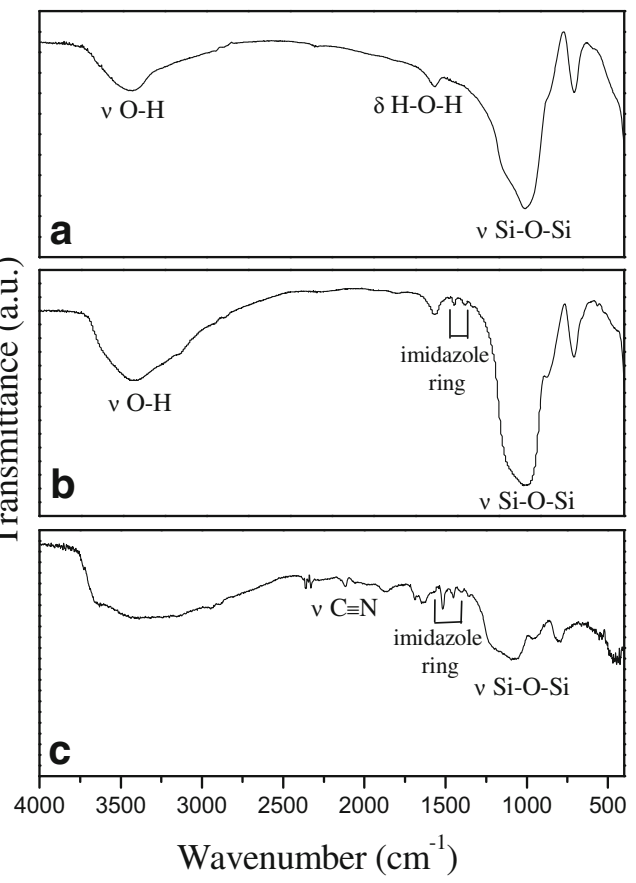

Fig. 2 Vibrational spectra in the infrared region: a SG, b SGI and c CdHSGI 
of $10.0 \mathrm{~s}$ and $6.0 \mathrm{~s}$ for ${ }^{29} \mathrm{Si}$ and ${ }^{13} \mathrm{C}$ respectively. All chemical shifts are reported in units (ppm) using tetramethylsilane (TMS) as external reference.

\subsubsection{Scanning Electron Microscopy}

The scanning electron microscopy of the materials was obtained using a JEOL JSM T-300 microscope. The samples were adhered to aluminum holders.

\subsubsection{Surface Area and Porosity}

The physical characteristics such as surface area and 3chloropropyl silica gel porosity before and after organofunctionalization with imidazole were determined by nitrogen adsorption-desorption isotherms by the BET method (Brunauer-Emmett-Teller), which is a standard procedure much used to determine such characteristics. The pore distribution was determined by the BJH method (Barrett-JoynerHalenda). Analyses were performed using a physicochemical apparatus Micrometritics ASAP 2010.

\section{Results and Discussion}

In the preparation of 3-chloropropyl silica gel, the 3-chloropropyltrimethoxysilane reacted with the silanol groups present on the silica gel surface via methoxy groups. The 3-chloropropyl silica gel appeared as a white
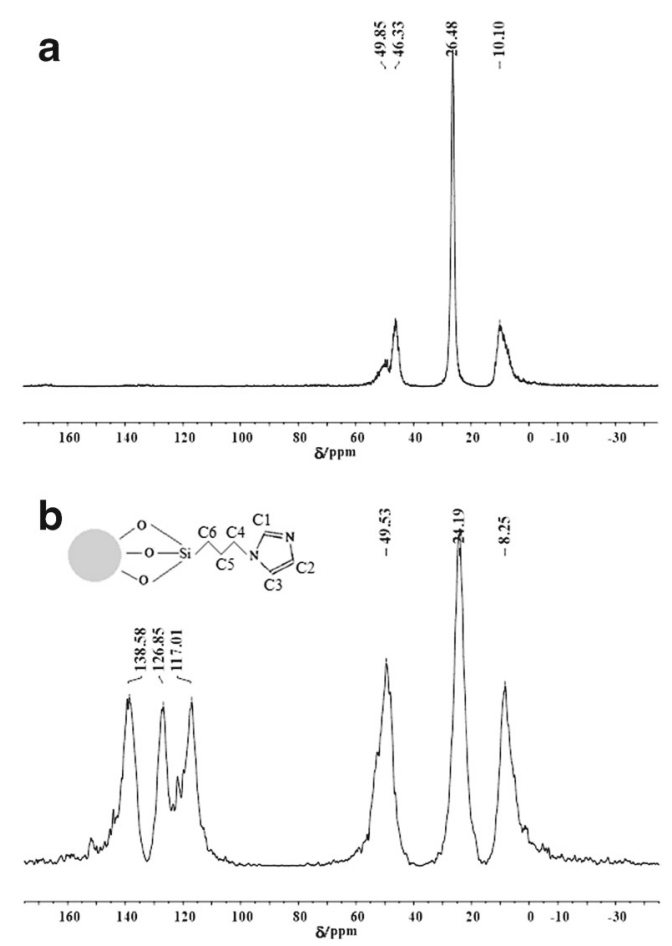

Fig. 3 Solid state NMR of ${ }^{13} \mathrm{C}$ for SG (a) and SGI (b) solid. Subsequently, in the organofunctionalization of 3chloropropyl silica gel with imidazole groups, the chlorine atom $(\mathrm{Cl})$ of the structure is very reactive and it is easily replaced by stronger bases, and it is a likely center for nucleophilic attack [23]. The connection of the imidazole with the matrix occurs probably through the nitrogen atom at position 1. Organofunctionalization resulted in a solid with light yellow color, described here as SGI.

The vibrational spectrum of 3-chloropropyl silica gel, illustrated in Fig. 2a shows a broad band in the region between 3000 and $3700 \mathrm{~cm}^{-1}$ which is related to $\mathrm{OH}_{(\nu \mathrm{O}-\mathrm{H})}$ stretching of silanol groups and remains of adsorbed water [2] and a band at $\sim 1635 \mathrm{~cm}^{-1}$ corresponding to the angular deformation of water molecules $(\delta \mathrm{HOH})$. Also are observed vibrations at $\sim 1100 \mathrm{~cm}^{-1}$ which are attributed to the chain $\mathrm{Si}-\mathrm{O}-\mathrm{Si} i_{(\nu \mathrm{Si}-\mathrm{O}-\mathrm{Si})}$ vibrations present in the silica structure [24, 25].

Figure $2 \mathrm{~b}$ and $\mathrm{c}$ illustrate the spectra in the infrared region for SGI and CdHSGI, respectively. In these spectra characteristics of precursor materials were observed as bands at $\sim 1100 \mathrm{~cm}^{-1}$ present in the silica structure. Axial
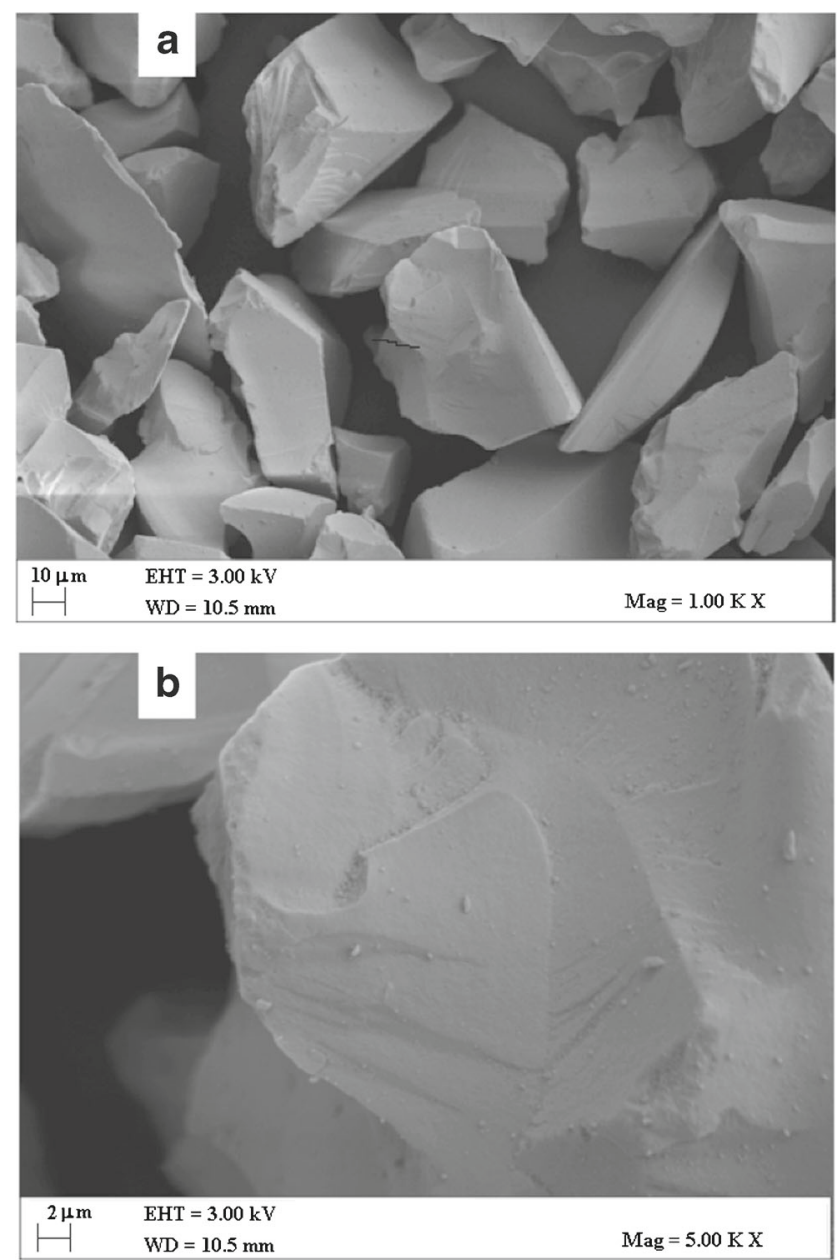

Fig. 4 SEM images of SG at a $1000 X$ and b $5000 X$ 
deformation vibrations of the imidazole ring bonds, which occur in the region between 1400 and $1550 \mathrm{~cm}^{-1}$, also were observed. In addition, it is possible to observe vibrations at $\sim 2110 \mathrm{~cm}^{-1}$, which are attributed to $\mathrm{C} \equiv \mathrm{N}_{(\nu \mathrm{C} \equiv \mathrm{N})}$ stretching, characteristic of the precursor potassium hexacyanoferrate, in the CdHSGI spectrum [24].

Figure $3 \mathrm{a}$ and $\mathrm{b}$ show the spectrum of the ${ }^{13} \mathrm{C}$ nuclear magnetic resonance at solid state (MAS-NMR) for all studied materials. The three $\mathrm{CH}_{2}$ groups $(\alpha, \beta, \gamma)$ to the terminal silicon atom (a), are clearly seen in the ${ }^{13} \mathrm{C}$-NMR $\left(\alpha-\mathrm{CH}_{2}\right.$ at $10.1, \beta-\mathrm{CH}_{2}$ at 26.4 , and $\gamma-\mathrm{CH}_{2}$ at $49.8 \mathrm{ppm}$ ). After the 3 -chloropropyl silica modification with imidazole groups (Fig. 3b) these resonances in the aliphatic region shifted upfield, as seen in the ${ }^{13} \mathrm{C}-\mathrm{NMR}\left(\alpha-\mathrm{CH}_{2}\right.$ at $8.2, \beta-\mathrm{CH}_{2}$ at 24.2 , and $\gamma-\mathrm{CH}_{2}$ at $49.5 \mathrm{ppm}$ ). The carbon atom attached to the electropositive $\mathrm{Si}$ group $\left(\alpha-\mathrm{CH}_{2}\right)$ is more shielded and therefore shows an upfield shift resulting in the peak at 8.25 $\mathrm{ppm}$. In the aromatic region, three resonance peaks at 138.5 (C1); $126.8(\mathrm{C} 2)$ and $117.0(\mathrm{C} 3)$ ppm are observed and these results are in concordance with reports in the literature $[26,27]$.
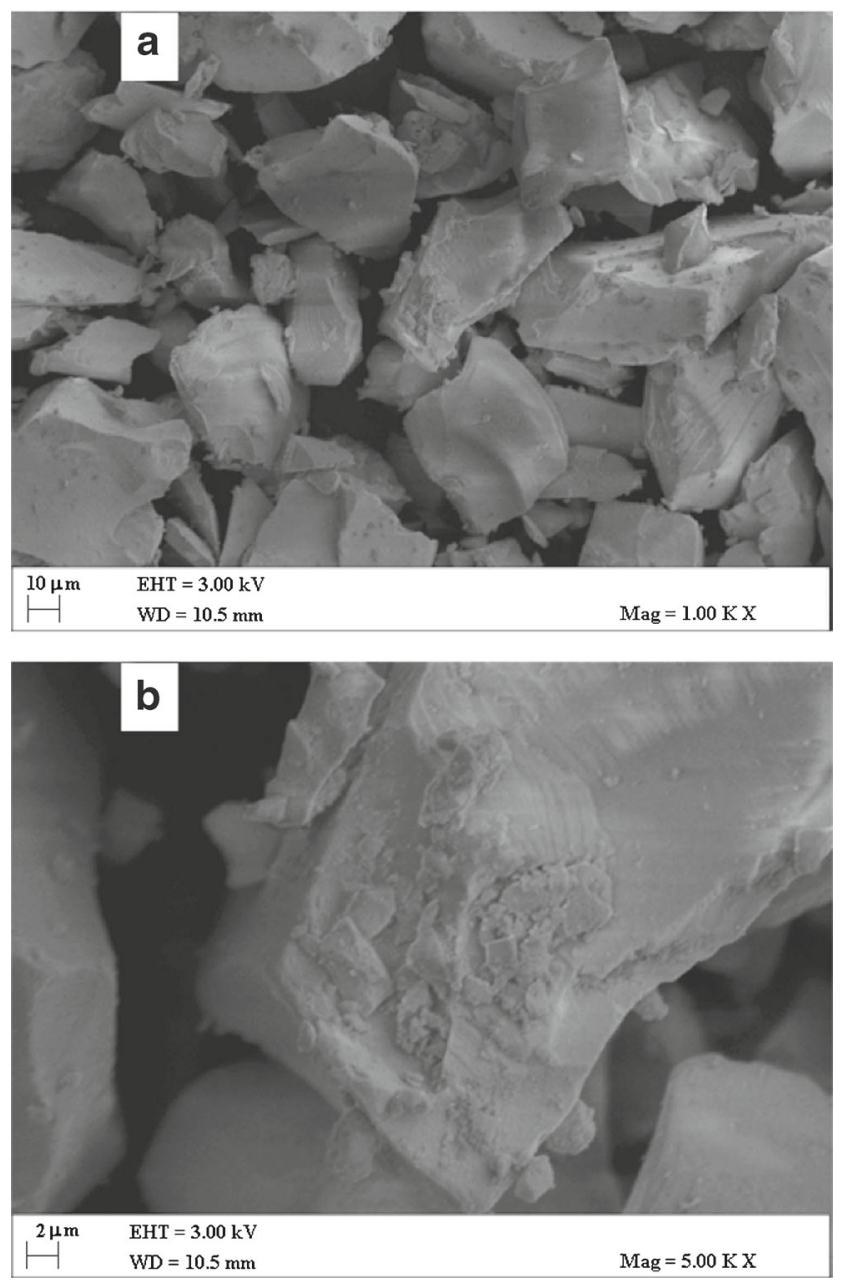

Fig. 5 SEM images of SGI at a $1000 \mathrm{X}$ and b $5000 \mathrm{X}$
In the ${ }^{29} \mathrm{Si}$ (MAS-NMR) (spectrum not shown here) of the SG and SGI materials there were four relevant peaks at $-114,8,-112.2,-101.7,-54.6$, and $-64.4 \mathrm{ppm}$. The peaks at $(\delta)$ -112.2 and $-101.7 \mathrm{ppm}$ can be assigned as the $\mathrm{Q} 4$ [Si(OSi) 4 ] and $\mathrm{Q} 3\left[\mathrm{Si}(\mathrm{OSi})_{3} \mathrm{OH}\right]$ sites of silica. The silica spectrum has already been reported in the literature and is known to have peaks at $-109,-100$, and $-91 \mathrm{ppm}$ corresponding to the $\mathrm{Q} 4$, Q3, and Q2 [Si- $\left.(\mathrm{OSi})_{2}(\mathrm{OH})_{2}\right][28,29]$.

The T3 structural unit which corresponds to the peak at ( $\delta)$-64.4 ppm indicates the formation of a Si-O-Si linkage of the imidazolin-1-propyl group on the surface silica silicon atoms through three siloxane bonds. The T2 structural unit gives a peak at around $-60 \mathrm{ppm}$, and the remaining OEt group of triethoxychloropropylsilane that is not anchored onto the surface of sílica may undergo hydrolysis to form a Si-OH species on the support. The relatively high peak intensity at $-64.4 \mathrm{ppm}$ (T3 structural unit) confirms that the imidazole groups have attached to the silica surface [30, 31].

Scanning electron micrographs of SG and SGI in Figs. 4 and 5, respectively, were obtained at $1000 \times$ and $5000 \times$ magnification. Apparently, the 3-chloropropyl silica gel surface is smooth and becomes rough presenting fouling after the modification reaction. It was observed that the particle appearance and size of both samples were similar, demonstrating that the silica gel particles had good mechanical stability and they had not been destroyed during the whole reaction. Furthermore, it is clear that the functional groups were distributed on the whole surface and may block part of the pore region, verified also by the surface area analysis.
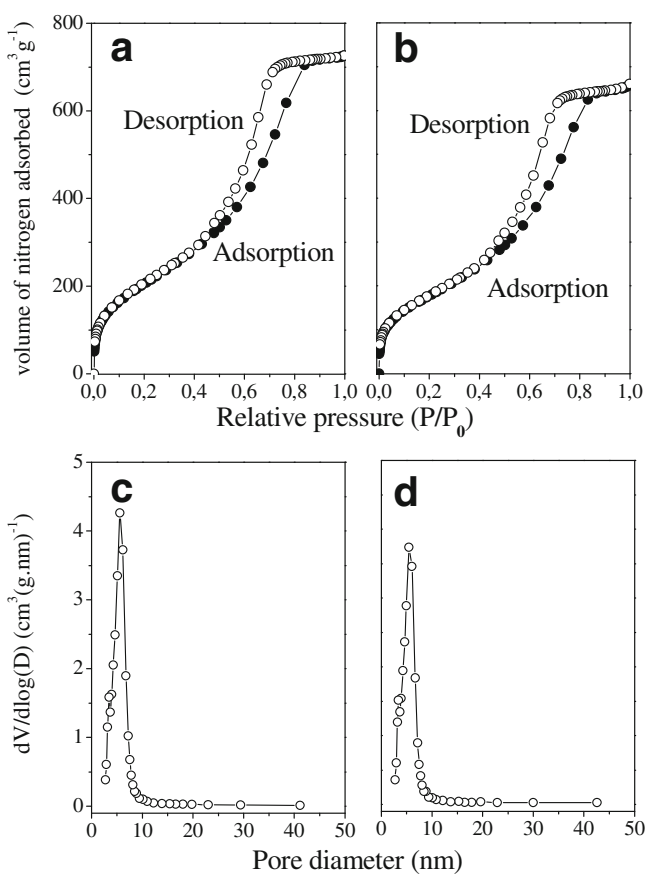

Fig. 6 BET nitrogen adsorption-desorption isotherms of a SG and b SGI and BJH sorption pore size distributions of $\mathbf{c}$ SG and $\mathbf{d}$ SGI 
Table 1 Parameters of porous structure of SG and SGI

\begin{tabular}{llll}
\hline Samples & $\begin{array}{l}\text { BET surface area } \\
\left(\mathrm{m}^{2} \mathrm{~g}^{-1}\right)\end{array}$ & $\begin{array}{l}\text { Volume of pores } \\
\left(\mathrm{cm}^{3}(\mathrm{~g} \mathrm{~nm})^{-1}\right)\end{array}$ & $\begin{array}{l}\text { BJH sorption average pore } \\
\text { size }(\mathrm{nm})\end{array}$ \\
\hline SG & 778 & 4.3 & 5.6 \\
SGI & 669 & 3.7 & 5.2 \\
\hline
\end{tabular}

The IV isotherm type is characterized by having a hysteresis curve that is associated with capillary condensation. This isotherm type is presented by many industrial mesoporous adsorbents. Isotherms with $\mathrm{H} 1$ isotherm type present both nearly vertical and parallel curves within a considerable range of gas uptake [32]. The nitrogen adsorptiondesorption isotherms for SG and SGI are shown in Fig. 6a and $b$. From the isotherms it is seen that the amount of nitrogen adsorbed increases at a medium relative pressure $\left(\mathrm{p} / \mathrm{p}_{0}\right)$ indicating capillary condensation of nitrogen within the uniform mesoporous structure, which confirms the characteristic of both materials having a IV isotherm type with $\mathrm{H} 1$ isotherm type. The two lines are approximately parallel indicating that the silica pores have radii nearly uniform and are open, which is very favorable for reactions carried out on the silica gel surface $[2,32]$. It was also observed that the volume of nitrogen adsorbed decreased with functionalization, meaning that there was a decrease in size and pore volume due to organic molecules immobilization. Accordingly, there was a decrease in surface area (BET) of SGI $\left(669 \mathrm{~m}^{2} \mathrm{~g}^{-1}\right)$ in relation to the $\mathrm{SG}\left(778 \mathrm{~m}^{2} \mathrm{~g}^{-1}\right)$, as is listed in Table 1.

The pore size distributions (BJH) of the silica gel SG and its derivative SGI are shown in Fig. $6 \mathrm{c}$ and d, where it can be seen that the average pore size is about 5.6 and 5.2 $\mathrm{nm}$ for SG and SGI, respectively. In the reaction process, the quantity of pores gradually became smaller and the size distribution of pores decreased.

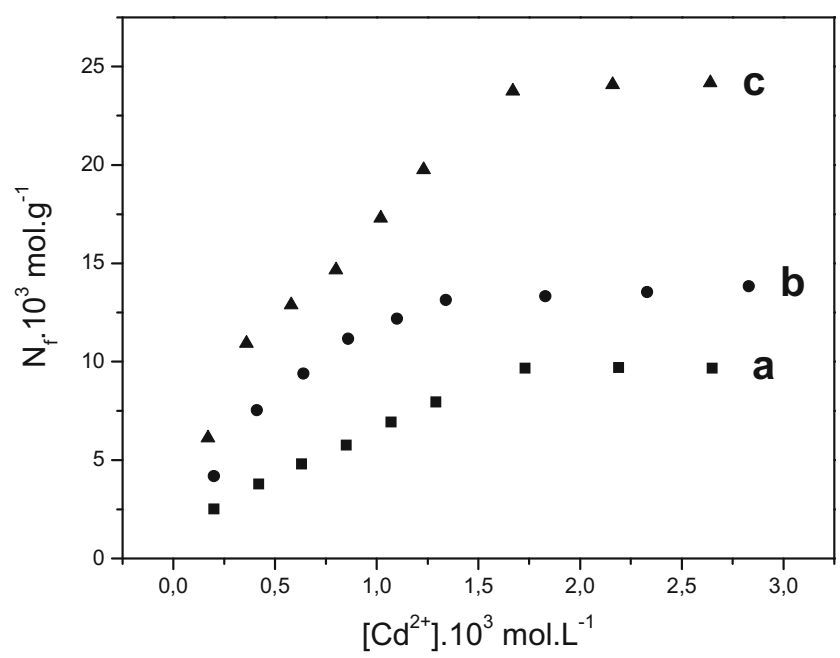

Fig. 7 Adsorption of $\mathrm{Cd}^{2+}$ ions in different concentrations in the media: a aqueous, b ethanol $42 \%$ and c ethanol $99 \%$
An analysis using the classical Kjeldahl method [20] was performed to determine nitrogen percentage in the SGI organofunctionalized material. The result obtained was $2.3 \%$ nitrogen.

For the SGI each molecule of the modifier attached to the silica surface has 2 nitrogen atoms in its structure; thus dividing the nitrogen percentage in the elemental analysis obtained for the molecular mass of nitrogen atoms contained in one molecule $\left(2.3 \times 10^{-2} / 2 \times 14 \mathrm{~g} \mathrm{~mol}^{-1}\right)$ we get a result of $8.2 \times 10^{-4}$ moles of nitrogen groups per gram of functionalized materials.

The evaluation results for metal ions adsorption capacity in different media (aqueous, ethanol $42 \%$ and ethanol 99\%) were obtained through adsorption isotherms by plotting $N_{f}$ against $C$, where $C$ is the equilibrium concentration of the solute in solution phase. Figure $7 \mathrm{a}, \mathrm{b}$ and $\mathrm{c}$ illustrate the adsorption isotherms for cadmium ions from different solvents onto the SGI surface.

The values of the maximum amount adsorbed $\left(N_{f}\right)$ in the concentration range tested for $\mathrm{Cd}^{2+}$ ions were $9.7 \times 10^{-5}$ mol g ${ }^{-1}, 13.8 \times 10^{-5} \mathrm{~mol} \mathrm{~g}^{-1}$ and $24.2 \times 10^{-5} \mathrm{~mol}$

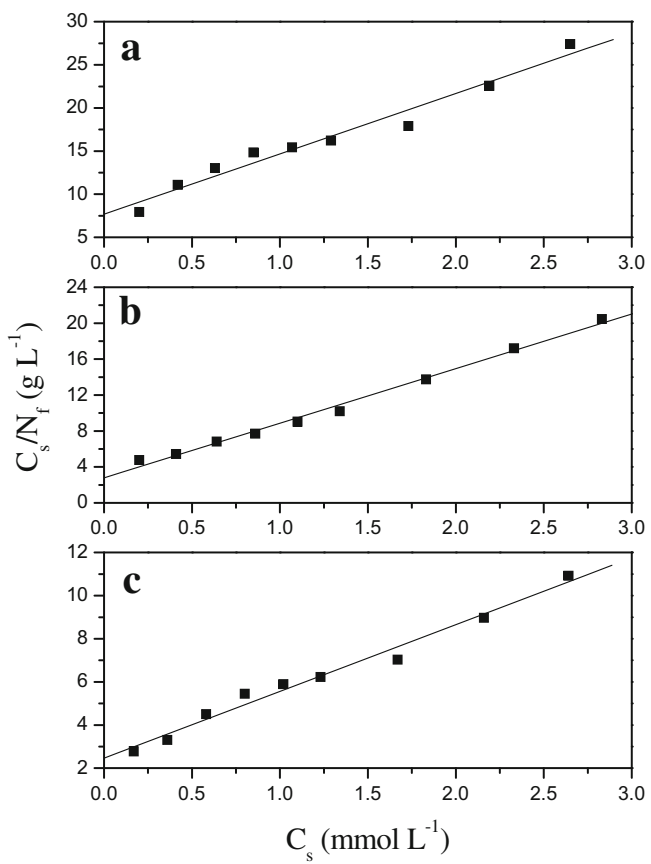

Fig. 8 Adsorption isotherms of $\mathrm{Cd}^{2+}$ ions in several solvents solutions on SGI as plot of $C_{s} / N_{f}$ against $C_{s}$ at $25 \pm 1{ }^{\circ} \mathrm{C}$ : a aqueous, b ethanol $42 \%$ and $c$ ethanol $99 \%$ 
Table 2 Adsorption of metal ions by SGI from different solvents at $25 \pm 1{ }^{\circ} \mathrm{C}$ and the corresponding correlation coefficients $(r)$

\begin{tabular}{llllll}
\hline Metallic ion & Solvent & $N_{f}^{\text {máximo }} .105\left(\mathrm{~mol} \mathrm{~g}^{-1}\right)$ & $N_{s} .10^{5}\left(\mathrm{~mol} \mathrm{~g}^{-1}\right)$ & $k .10^{-3}\left(\mathrm{~L} \mathrm{~mol}^{-1}\right)$ & $R$ \\
\hline \multirow{3}{*}{$\mathrm{Cd}^{2+}$} & Water & 9.71 & 14.29 & 0.911 & 0.983 \\
& Water/ethanol 42\% & 13.83 & 16.44 & 2.175 & 0.996 \\
& Ethanol 99\% & 24.17 & 32.29 & 1.258 & 0.990 \\
\hline
\end{tabular}

$\mathrm{g}^{-1}$ for aqueous solution, ethanol $42 \%$ and ethanol $99 \%$, respectively.

Equation 2 shows a schematic representation of the equilibrium that occurs between the $\mathrm{SGI}$ and $\mathrm{CdCl}_{2}$.

SGI . solvent $+\mathrm{CdCl}_{2}$. solvent $\rightleftarrows \mathrm{SGI}$. $\mathrm{CdCl}_{2}$. solvent + solvent

Based on the results, the SGI has an excellent potential for adsorption of the metal ions studied in different media, presenting a greater adsorbent capacity in ethanol $99 \%$, followed by ethanol $42 \%$ and finally, in aqueous medium.

More information about the system behavior can be obtained from a fit of the data to the modified Langmuir equation represented by Eq. 3, from which one can obtain the linearization curve $[33,34]$.

$\frac{C_{s}}{N_{f}}=\frac{C_{s}}{N_{s}}+\frac{1}{k N_{s}}$

In this equation, $C_{S}$ is the concentration of the solution at equilibrium $\left(\mathrm{mol} \mathrm{L}^{-1}\right), N_{f}$ the quantity of solute adsorbed by the material ( $\mathrm{mol} \mathrm{g}^{-1}$ ), $N_{s}$ is the adsorption capacity (mol g ${ }^{-1}$ ) and $k$ is the equilibrium constant. Plotting $C_{s} / N_{f}$ against $C_{s}$ allows the slope and intercept to be determined from which $N_{s}$ and $k$ are calculated. Figure $8 \mathrm{a}, \mathrm{b}$

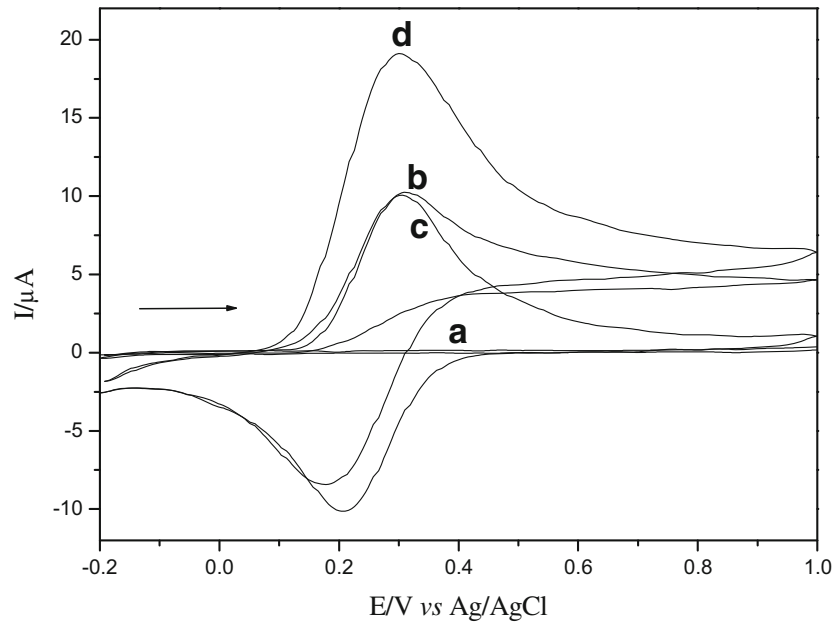

Fig. 9 Cyclic voltammograms of a graphite paste electrode, b graphite paste electrode in $9.0 \times 10^{-4} \mathrm{~mol} \mathrm{~L}^{-1}$ ascorbic acid, $\mathbf{c}$ graphite paste electrode modified with CdHSGI and $\mathbf{d}$ graphite paste modified with CdHSGI in $9.0 \times 10^{-4} \mathrm{~mol} \mathrm{~L}^{-1}$ of ascorbic acid. $\left(\mathrm{NaNO}_{3} 1.0\right.$ $\mathrm{molL}^{-1}$; $\mathrm{pH} 7.0, \mathrm{v}=20 \mathrm{mV} \mathrm{s}^{-1}$ ) and c represent the linearized Langmuir isotherms for the $\mathrm{SGI}$ in the solvents studied for $\mathrm{Cd}^{2+}$ ions.

Table 2 list the parameters calculated from adsorption in $\mathrm{CdCl}_{2}$ solution onto the SGI surface. The results show that there is proximity between the experimental values and empirical Langmuir isotherms. High values obtained for the equilibrium constant, in the order of magnitude of $10^{3} \mathrm{~L}$ $\mathrm{mol}^{-1}$, suggest that the complexes formed on the adsorbent surface are thermodynamically stable [35]

Complex CdSGI and CdHSGI were characterized by cyclic voltammetry. The cyclic voltammogram of CdHSGI exhibited only one redox pair with a midi potential $\mathrm{E}^{\theta^{\prime}}=0.25 \mathrm{~V}$, attributed to the redox process $\mathrm{Fe}^{2+}(\mathrm{CN})_{6} / \mathrm{Fe}^{3+}(\mathrm{CN})_{6}$.

Figure 9 illustrates the electrocatalytic oxidation of ascorbic acid at the graphite paste electrode modified with CdHSGI. It was observed that the graphite paste electrode (a) did not show any redox pair in the potential range between -0.2 and $1.0 \mathrm{~V}$ in the absence of ascorbic acid, however, in the presence of ascorbic acid (b) it showed an oxidation peak at $0.31 \mathrm{~V}$. The graphite paste electrode modified with CdHSGI (c) exhibited a redox pair with $\mathrm{E}^{\theta^{\prime}}=$ $0.14 \mathrm{~V}$ in the absence of ascorbic acid, and in the presence of ascorbic acid (d) there was an increase in the anodic peak current intensity, followed by a decrease of the cathodic

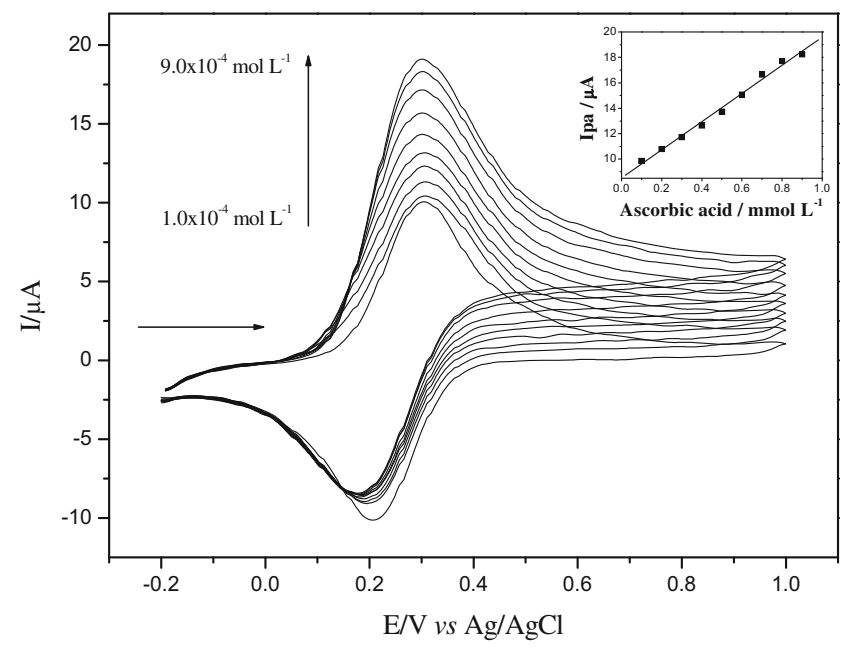

Fig. 10 Cyclic voltammograms obtained for the graphite paste electrode modified with CdHSGI in the presence of different ascorbic acid concentrations $\left(1.0 \times 10^{-4}\right.$ to $\left.9.0 \times 10^{-4} \mathrm{~mol} \mathrm{~L}^{-1}\right)$. $\left(\mathrm{NaNO}_{3} 1.0\right.$ $\left.\mathrm{molL}^{-1} ; \mathrm{pH} 7.0, \mathrm{v}=20 \mathrm{mV} \mathrm{s}^{-1}\right)$ 
Table 3 Comparison of this work with previous reports of ascorbic acid detection

\begin{tabular}{lllll}
\hline Electrode material & Technique & Linear range (M) & Limit detection (M) & Reference \\
\hline G-MWCNT/THAI-I2PE / GPE $^{\mathrm{a}}$ & $\mathrm{CV}^{\mathrm{b}}$ & $5.6 \times 10^{-5}$ to $1.2 \times 10^{-2}$ & $3.6 \times 10^{-5}$ & {$[36]$} \\
MWCNT / GPE $^{\mathrm{a}}$ & $\mathrm{CV}^{\mathrm{b}}$ & $5.0 \times 10^{-5}$ to $5.0 \times 10^{-6}$ & $3.4 \times 10^{-5}$ & {$[37]$} \\
2,7-BFEFOMCPE / GPE & $\mathrm{CV}^{\mathrm{b}}$ & $5.0 \times 10^{-5}$ to $2.6 \times 10^{-3}$ & $1.8 \times 10^{-5}$ & {$[38]$} \\
CdHSGI / GPE $^{\mathrm{a}}$ & $\mathrm{CV}^{\mathrm{b}}$ & $1.0 \times 10^{-4}$ to $9.0 \times 10^{-4}$ & $7.9 \times 10^{-5}$ & This work \\
\hline
\end{tabular}

${ }^{\text {a }}$ graphite paste electrode

${ }^{\mathrm{b}}$ Cyclic Voltammetry

peak current, and a decrease in the oxidation potential of ascorbic acid $(20 \mathrm{mV})$.

Figure 10 shows the CdHSGI voltammetric behavior in different ascorbic acid concentrations and the analytic curve of the anodic current as a function of ascorbic acid concentration for CdHSGI (see graph insert in Fig. 10). The modified graphite paste electrode showed a linear response in the concentration range of $1.0 \times 10^{-4} \mathrm{~mol} \mathrm{~L}^{-1}$ to 9.0 $\times 10^{-4} \mathrm{~mol} \mathrm{~L}^{-1}$ with a corresponding equation $\mathrm{Y}(\mu \mathrm{A})=$ $8.5+11.1 \times 10^{3}$ [ascorbic acid] and a correlation coefficient $R=0.996$. The detection limit was $7.9 \times 10^{-5} \mathrm{~mol}$ $\mathrm{L}^{-1}$ with a relative standard deviation of $\pm 3 \%(n=3)$ and amperometric sensitivity of $11.1 \mathrm{~mA} / \mathrm{mol} \mathrm{L}^{-1}$.

The anodic current intensity increases due to the electrocatalytic oxidation of ascorbic acid. $\mathrm{Fe}^{3+}$ produced during the anodic scan, chemically oxidizes the ascorbic acid, whereas $\mathrm{Fe}^{3+}$ is reduced to $\mathrm{Fe}^{2+}$, which will again be electrochemically oxidized to $\mathrm{Fe}^{3+}$. For this system, the electrocatalytic process can also be represented according to the Eqs. 4 and 5:

$\left\{\mathrm{Na}_{4}\left[\mathrm{Fe}^{\mathrm{II}}(\mathrm{CN})_{6}\right]\right\}_{2} \rightleftarrows\left\{\mathrm{Na}_{3}\left[\mathrm{Fe}^{\mathrm{III}}(\mathrm{CN})_{6}\right]\right\}_{2}+2 \mathrm{Na}^{+}+2 \mathrm{e}^{-}$

$\left.\left.\qquad \mathrm{Na}_{3}\left[\mathrm{Fe}^{\mathrm{III}}(\mathrm{CN})_{6}\right]\right\}_{2}+2 \mathrm{Na}^{+}+\mathrm{AA}^{-} \rightleftarrows \mathrm{Na}_{4}\left[\mathrm{Fe}^{\mathrm{II}}(\mathrm{CN})_{6}\right]\right\}_{2}+\mathrm{DAA}^{-}+2 \mathrm{H}^{+}$
$=\mathrm{SGICd}$

where AA- and DAA- correspond to the dissociated forms of ascorbic acid and of dehydroascorbic acid, respectively.

Table 3 presents a comparison of similar reports in the literature for ascorbic acid detection. These results show the analytical benefits obtained by the use of CdHSGI, which showed a good limit of detection when compared with previous reports.

\section{Conclusions}

The 3-chloropropyl silica gel (SG) synthesis and its functionalization with the imidazole ligand were performed with success. The material obtained (SGI), is shown to be an adequate matrix to (transition metals sorption) in several solvents. The excellent adsorptive capacity $\left(9.7 \times 10^{-5}\right.$ to $24.2 \times 10^{-5} \mathrm{~mol} \mathrm{~g}^{-1}$ ) make it a potential candidate for applications in removing and preconcentration of metallic ions from real samples, such as alcohol fuel and beverages, whose alcohol content is about $42 \%$.

Additionally, the hybrid composite SGI after cadmium adsorption and subsequent hexacyanoferrate (CdHSGI) reaction was used to prepare chemically modified electrodes and applied in the electrocatalytic detection of ascorbic acid. In this context, the cyclic voltammogram of the modified graphite paste electrode with CdHSGI showed one redox couple with formal potential $\mathrm{E}^{\theta^{\prime}}=0.25 \mathrm{~V}$ ( vs Ag/AgCl, $\mathrm{NaNO}_{3} 1.0 \mathrm{~mol} \mathrm{~L}-1 ; v=20 \mathrm{mVs}^{-1}$ ), attributed to the redox process $\mathrm{Fe}^{2+}(\mathrm{CN})_{6} / \mathrm{Fe}^{3+}(\mathrm{CN})_{6}$. The modified electrode gives a linear range from $1.0 \times 10^{-4} \mathrm{~mol} \mathrm{~L}^{-1}$ to $9.0 \times 10^{-4} \mathrm{~mol} \mathrm{~L}^{-1}(R=0.996)$ for the ascorbic acid determination with a detection limit of $7.9 \times 10^{-5} \mathrm{~mol}$ $\mathrm{L}^{-1}$ with a relative standard deviation of $3 \%(n=3)$ and amperometric sensitivity of $11.1 \mathrm{~mA} / \mathrm{mol} \mathrm{L}^{-1}$ for ascorbic acid. The graphite paste electrode with CdHSGI was electrochemically stable for 8 months.

In general, the materials prepared are potential candidates for metal ions removal and separation in various media, as well as electrochemical sensors for the detection of ascorbic acid.

Acknowledgments The authors would like to express their gratitude for the financial support by the Fundação de Amparo à Pesquisa do Estado de São Paulo (FAPESP- Processes 2012/05438-1; 2013/08495-9; 2012/11306-0) and Conselho Nacional de Desenvolvimento Científico e Tecnológico (CNPq) Process: 306087/2012-0.

\section{References}

1. Dias Filho NL, do Carmo DR (2006) Adsorption at silica, alumina, and related surfaces. In: Hubbard AT (ed) Encyclopedia of surface and colloid science. 2nd edn. Taylor \& Francys, New York, pp 209-228

2. Yin P, Tian Y, Wang Z, Qu R, Liu X, Xu Q, Tang Q (2011) Mater Chem Phys 129:168-175 
3. Xu Q, Yin P, Zhao G, Yin G, Qu R (2010) Cent Eur J Chem 8:214222

4. Song Y, Ou H, Bian W, Zhang Y, Pan J, Liu Y, Huang W (2013) J Inorg Organomet Polym 23:1325-1334

5. Yin P, Wang C, Yang Y, Tian Y, Yu Z (2011) J Chem Eng Data 56:450-457

6. Zhang Y, Qu R, Sun C, Chen H, Wang C, Ji C, Yin P, Sun Y, Zhang H, Niu Y (2009) J Hazard Mater 163:127-135

7. Bhatnagar A, Sharma PK, Kumar N (2011) Int J PharmTech Res 3:268-282

8. Shalini K, Sharma PK, Kumar N (2010) Der Chemica Sinica 1:3647

9. Joseph A, Ramamurthy PC, Subramanian S (2011) J Appl Polym Sci 123:526-534

10. Yin P, Xu Q, Qu R, Zhao G, Sun Y (2010) J Hazard Mater 173:710-716

11. Casella IG, Guascito MR (1997) Electroanalysis 9:1381-1386

12. Malinauskas A, Garjonytè R, Mažeikienè R, Jurevičiūtè I (2004) Talanta 64:121-129

13. Raoof JB, Ojani R, Beitollahi H (2007) Int J Electrochem Sci 2:534-548

14. Shekhovtsova TN, Muginova SV, Luchinina JA, Galimova AZ (2006) Anal Chim Acta 573-574:125-132

15. Suntornsuka L, Gritsanapunb W, Nilkamhankb S, Paochomb A (2002) J Pharm Biomed Anal 28:849-855

16. Mitic SS, Kostic DA, Naskovic-dokic DC, Mitic MN (2011) Trop J Pharm Res 10:105-111

17. Markarian SA, Sargsyan HR (2011) J Appl Spectrosc 78:6-10

18. da Silveira TFS, Silvestrini DR, Bicalho UO, do Carmo DR (2013) Int J Electrochem Sci 8:872-886

19. do Carmo DR, Paim LL, Silvestrini DR, Sá AC, Bicalho UO, Stradiotto NR (2011) Int J Electrochem Sci 6:11751188

20. do Carmo DR (1988) Utilização de Materiais Porosos com superfícies modificadas com grupos organofuncionais na extração de $\mathrm{Cu}$ (II) nas aguardentes Trabalho de Conclus ão de Curso,
Instituto de Química de Araraquara, Universidade Estadual Paulista "Júlio de Mesquita Filho"

21. Rao BM, Shetty AN (1998) Microchim Acta 130:103-104

22. Soares LA, da Silveira TFS, Silvestrini DR, Bicalho UO, Dias Filho NL, do Carmo DR (2013) Int J Electrochem Sci 8:46544669

23. Allinger NL, Cava MP, Jongh DC, Johnson CR, Lebel NA, Stevens CL (1976) Química orgânica. LTC, Rio de Janeiro

24. Silverstein RM, Welbster FX (1996) Spectrometric identification of organic compounds. Wiley, New York

25. Iler RK (1979) The chemistry of silica. Willey, New York

26. Aany Sofia LT, Krishnan A, Sankar M, Kala Raj NK, Manikandan P, Rajamohanan PR, Ajithkumar TG (2009) J Phys Chem C 113:21114-21122

27. Fyfe CA, Gobbi GC, Kennedy GJ (1985) J Phys Chem 89:277281

28. Brei VV (1994) J Chem Soc, Faraday Trans 90:2961-2964

29. Bergna HE, Roberts WO (2006) Colloidal silica: fundamentals and applications, vol 131. CRC Press, Boca Raton

30. Harrison PG (1997) J Organomt Chem 542:141-183

31. Urich KE, Cannizzaro SM, Langer RS, Shakesheff KM (1999) Chem Rev 99:3181-3198

32. Sing KSW, Everett DH, Haul RAW, Moscou L, Pierotti RA, Rouquerol J, Siemieniewska T (1985) Pure Appl Chem 57:603619

33. Adamson WA (1990) Physical chemistry of surfaces, 5th ed. Wiley, New York

34. Langmuir I (1918) J Am Chem Soc 40:1361-1403

35. Rosa AH, Goveia D, Bellin IC, da Silva Lessa S, Dias Filho NL, de Magalhães Padilha P (2006) Anal Bioanal Chem 386:2153-2160

36. Noroozifar M, Khorasani-Motlagh M, Tavakkoli H (2011) Anal Sci 27:929-935

37. Goh JK, Tan WT, Lim FT, Maamor NAM (2008) Malaysian J Anal Sci 12:480-485

38. Raoof J-B, Ojani R, Beitollahi H (2007) Int J Electrochem Sci 2:534-548 